Acta vet. scand. $1973,14,341-343$.

Brief Communication

\title{
IN VITRO EFFECT OF BILE ON THE MOTILITY OF DICTYOCAULUS VIVIPARUS THIRD STAGE LARVAE
}

The effect of bile from cattle on the motility of third stage larvae of Dictyocaulus viviparus was studied in vitro. It was shown that larvae cultured at room temperature for 7 days and subsequently stored at $4^{\circ} \mathrm{C}$ for 2 weeks became active when exposed to bile.

Larvae were harvested from a calf with severe parasitic bronchitis. They were cultured at room temperature for 7 days and subsequently stored at $4^{\circ} \mathrm{C}$ in tap water. At the day of the experiment the larvae were 3 weeks old. One $\mathrm{ml}$ of the suspension contained 1000 larvae. By counting 50 larvae in 5 aliquots of $0.2 \mathrm{ml}$, $4-18 \%$ were more or less active, $70-85 \%$ were found to be coiled and passive and 5-15\% were straight, vacuolized, passive and were considered dead.

Bile was collected at the slaughter-house from randomly selected healthy cattle without macroscopic changes of the liver tissue and biliary system. At room temperature the bile was a clear green fluid with a specific gravity of 1.025 and a dry matter content of $10.35 \%$. Dilutions were made, containing 0.0-0.2 0.5-1-2-3-4-5-6-7-8-9-10-15 and $20 \%$ of bile in distilled water. The dilutions were stored at $-18^{\circ} \mathrm{C}$.

Of the larval suspension $0.2 \mathrm{ml}$ was added to $2 \mathrm{ml}$ of each of the bile dilutions in pointed bottom test tubes. After incubation at $38^{\circ} \mathrm{C}$, the sediment was transferred to a slide and examined in the stereomicroscope. Fifty larvae, including obviously dead ones, were counted and grouped as 1) larvae showing movements or, 2) larvae not showing movements within 3 sec. of examination.

The procedure for larvae in distilled water deviated from the above. After incubation these larvae were examined directly under the stereomicroscope in small petri dishes (diameter $50 \mathrm{~mm}$ ) because of poor sedimentation in the absence of bile.

In repeated experiments it was found that the larvae uncoiled either partially or completely and became active when exposed to bile (Fig. 1). 

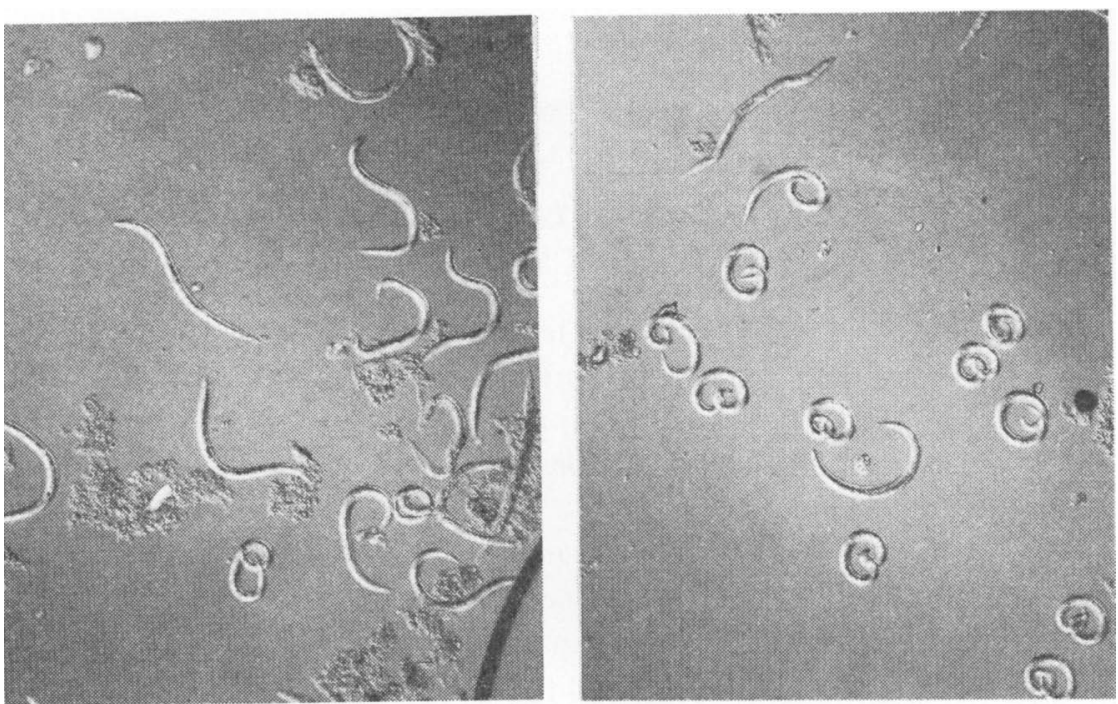

Figure 1. Larvae incubated in $4 \%$ bile (left) compared to larvae incubated in distilled water only (right).

per cent active

larvae

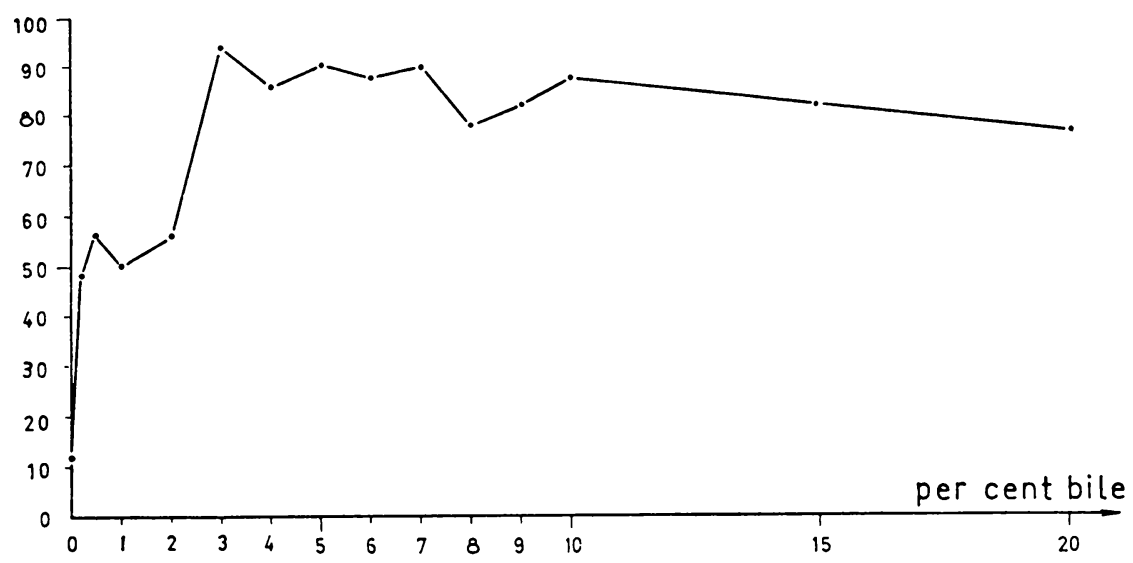

F i g u r e 2. Per cent active larvae after $60 \mathrm{~min}$. incubation in varying concentrations of bile. 
In most larvae the activation took place within $15 \mathrm{~min}$. and the larvae remained active for more than 4 hrs. The percentage of active larvae increased with increasing concentrations of bile until a plateau was reached at about $4 \%$. Results obtained after 60 min. incubation are shown in Fig. 2.

In evaluating the viability of larval suspensions, Prochazka \& Tomanek (1968) counted spontaneously motile larvae and coiled larvae and considered the remaining larvae non viable. Simultaneously they tested the infectivity on guinea-pigs and compared these results.

In addition to these two methods Cornwell \& Jones (1970) utilized the exsheathment test (Lapage 1933, Silverman \& Podger 1964 ) reasoning that in order to exsheath a larva must possess a certain vigour. However, these authors pointed out that the ability to exsheath is in no way analogous to the ability to infect guineapigs.

The described in vitro effect of bile provides a new way of evaluating the viability of larval suspensions. Furthermore, it indicates that bile plays an important role in the activation of ingested lungworm larvae in the intestine of the host.

\section{R. J. Jorgensen}

The Danish Agricultural and Veterinary Research Council, Parasitological Research Group,

Medical Clinic,

Royal Veterinary and Agricultural University,

Copenhagen, Denmark.

\section{REFERENCES}

Cornwell, R. L. \& R. M. Jones: Determination of viability and infectivity of Dictyocaulus viviparus larvae after storage. Res. Vet. Sci. 1970, 11, 484-485.

Lapage, G.: Cultivation of parasitic nematodes. Nature (Lond.) 1933, $131,583-584$.

Prochazka, Z. \& J. Tomanek: Some practical aspects on the production of radiation vaccines against helminthic diseases. Isotopes and Radiation in Parasitology, IAEA, Vienna 1968, $21-33$.

Silverman, P. H. \& K. R. Podger: In vitro exsheathment of some nematode infective larvae. Exp. Parasit. 1964, 15, 314 -324.

(Received January 17, 1973).

Reprints may be requested from: R. J. Jorgensen, Parasitological Research Group, Bülowsvej 13, DK-1870 Copenhagen V, Denmark. 